Alegre, I., Berbegal-Mirabent, J., \& Guerrero, A. (2019). Mission statements: what university research parks tell us about timing. Journal of Business Strategy. https://doi.org/10.1108/JBS11-2018-0191

\title{
Mission statements: What university research parks tell us about timing
}

Inés Alegre (IESE Business School)

Jasmina Berbegal-Mirabent (Universitat Internacional de Catalunya)

Adrián Guerrero (Universitat Internacional de Catalunya)

\section{Abstract}

Purpose: Mission statements are a key element of any organization. Ideally the mission statement should be written at the initial stages of an organization's life to be a useful tool to guide future organization's decisions and strategy. However, at the early stages of an organization's life, the organization might still be under development with the objective and stakeholders not yet well defined and therefore, stating the mission so early on, might neglect some important elements. In this paper, we explore the difference in mission statement quality between missions that have been created at the birth stage of an organization versus missions that are just explicitly formulated once the organization is already wellestablished and an underlying implicit mission already exists. We use as an empirical setting university research parks.

Design/methodology/approach: We evaluate mission statement quality using content analysis. We then test the differences on mission statement quality between two groups of research parks, those that have followed a creation strategy versus those that have followed a formulation strategy, using mean of differences test.

Findings: We find that a formulation strategy produces more complete mission statements than the creation strategy. Research parks that have followed a formulation strategy include in their mission statements more references to relevant stakeholders, such as investors, than parks following a creation strategy with respect to their mission statement.

Research limitations: The research setting is Spanish Science Parks. This research setting is appropriate to answer the research question as two Park creation strategies, planned and unplanned, allow the researchers to clearly differentiate between two mission conception strategies. However, the sample size is rather small. 
Practical implications: Research has shown that a well-defined mission helps organisations focus and strategy formulation. Our research offers some guidance on how to achieve a high-quality mission statement which will, in turn, help organisations have a better definition of their purpose.

Originality/value: Research until now has assumed that the mission statement should be formulated at the initial stages of the organisation's life. Our research shows that defining the mission statement later in the process creates higher quality mission statements that better reflect the organisations purpose and relevant stakeholders.

Keywords: Mission statement, research parks, knowledge and technology transfer organisations, formulation strategy, creation strategy.

\section{Introduction}

A mission statement is a declaration of an organization's reason for being that reveals what the organization wants to be and who it wants to serve (David 1989). In other words, mission statements specify an organization's product or service, markets, customers, and philosophy. The concept of mission statement was developed in the early 1980s when academics and managers recognized the importance of having a mission statement in all types of organizations proving that, when a mission statement is well created, it has a positive impact on the performance, values, organizational culture, and stakeholders.

Having a mission statement is believed to be the first step in a company strategic planning process. Only after a mission statement has been developed, can objectives and strategies be formed properly in all segments of a company. Although it is true that at the initial stages of a company life it is important to have very clear its main purpose in order to be able to formulate the appropriate strategy, it is also true that precisely at birth, companies face higher levels of uncertainty and that, in those cases, it is important for organizations to be flexible and to adapt and sometimes modify critical elements such as product, service, type of customers, target market, sales strategy or the like. Following this line of reasoning, two approaches can be valid with respect to mission statement design. First, some organizations might choose to create their mission statement right from the beginning, to use it as a light that guides strategic decisions. Second, other organizations might prefer to navigate through the uncertainty of the initial steps of an organization's life without clearly stating their mission, and, once the organization is settled and the mission becomes apparent, then do the exercise of 
formulating in a clear and concise way the mission that is already in practice. There are advantages and disadvantages of each option. In the first case, called here creation strategy, organizations have a mission statement to turn to in case of need, to focus and take consistent managerial decisions throughout the organization. In the second case, the organization might experience more flexibility and freedom but, at the same time, lacking a clear guidance, there is the risk of miss-alignment and lack of coherence among different parts of the organization or among different managers who take decisions in the organization. When organizations decide to write the mission statement later in the process, is then an exercise more of formulating than of creating the mission. In those cases, the organization has an implicit mission that just needs to be formulated explicitly, this strategy will be called formulation strategy. In the long term, though, both strategies will lead to having an organizational mission statement.

Mission statements need to be of high quality, that is, reflect in a clear but at the same time succinct way all what is important for the organization. Quality of the mission statement, independently on whether the mission statement is created early on or formulated once the company is more established, is an important characteristic as mission statements are usually relatively stable over time and should serve as a tool that managers can, and should, use when taking relevant decisions. This is precisely what motivates the research question of the present study: What strategy produces better mission statements: the creation strategy or the formulation strategy?

We explore this question in an interesting setting, that of university research parks. University research parks are a particular type of science parks, where universities offer spaces to researchers in order to facilitate the development of projects with market potential. In university research parks information flows from academia to business, accelerated by geographical proximity. Accordingly, they have become an important policy instrument to accelerate innovation. Specifically, they bridge the gap between the supply (technological offer: universities and research groups) and the demand side (private and public entities requiring university's knowledge and expertise) of technology (Leyden, Link \& Siegel, 2008). Today there are over 170 university research parks in North America, the UK Science Park Association reports more than 50, and more than 100 can be found in Asia. All these figures indicate that university research parks represent an international phenomenon.

According to Berbegal-Mirabent, Alegre and Guerrero (2017), not all parks respond to the same creation strategy. They distinguish between planned-parks and unplanned-parks. On the one hand, planned-parks are the result of the desire 
to create a park from scratch in an attempt to provide the university with a more dynamic environment. The university provides one or more buildings with the appropriate spaces, infrastructures and services to attract research groups, promoting their establishment or growth but also inducing firms and knowledgebased companies to join the project. On the other hand, unplanned-parks follow the logic of institutionalizing the endogenous character of a dynamic environment that emerged spontaneously in the surroundings of the university. This approach first begins by offering to existing research groups at the university basic service coverage for their daily activities. As these demands get sophisticated, external firms begin to show interest in being located also there. Consequently, specialized management units are required, leading to the formal constitution of the park. This research setting is ideal to explore the research question of this study as planned research parks are decided ex-ante and therefore their mission statement is created from the beginning while unplanned parks emerge spontaneously and are just formalized, and so their mission statement. This empirical setting will allow us to explore the differences in mission statements between planned and unplanned university research parks.

This study contributes to the literature on mission statements by raising the question of time in mission statement design. Until now, it has been assumed that the mission statement should be formulated at the birth of an organization. This study explores whether this assumption is true, arriving to the conclusion that, actually, formulating the strategy later on, creates better quality mission statements. The company has gained experience on the market and is able to define more appropriately the relevant stakeholders than organizations that follow the creation strategy. Second, this paper contributes as well to the literature on research parks and technology transfer as little research has been done exploring its mission statements and the quality of them. Finally, this study is also relevant for practitioners and entrepreneurs as it gives some hints on the advantages and disadvantages of mission statement creation versus mission statement formulation.

\section{Mission statements: purpose and components}

Mission statements have been under review since the late 1980s. A mission statement is an enduring statement of purpose that reveals an organization's product or service, markets, customers, and philosophy (for a comprehensive review on mission statements see Alegre et al. (2018)). Firms need to establish their goals and strategy. Having a mission statement is believed to be the first step in this strategic planning process. Only after a mission statement has been developed can objectives and strategies appropriate be formed properly in all 
segments of a company (Ireland and Hitt 1992).

According to Bartkus, Glassman, and McAfee (2000), mission statements fulfil several organizational needs. First, missions may be a public declaration of the firm's direction, stating where the firm is heading and therefore mission statements serve as a tool to provide guidance and direction. Second, mission statements may also serve as a control mechanism by identifying boundaries that prevent a firm from engaging in unrelated or inappropriate business activities. Third, mission statements can assist employees in making non-routine decisions by expressing the firm's values and culture. Finally, mission statements can motivate and inspire employees by creating a shared sense of purpose.

To assess the quality of mission statements different approaches have been taken. These approaches are well summarized in Bartkus, Glasman and McAfee (2006) who identify three measures to properly assess the quality of mission statements: (i) references to organization's stakeholders; (ii) inclusion of multiple components; (iii) reference to organizational objective. Those quality measures are therefore focused on the completeness of the mission statement. A mission statement is considered of high quality if it contains all relevant stakeholders, the main purpose of the organization is stated, and it contains several important components. Including the most critical stakeholders in the mission statement help executives focus their efforts and consequently have a positive impact on firm's performance.

In the context of university research parks, we hypothesize that unplanned parks, those that followed an entrepreneurial route, will have a higher quality mission statement than planned parks. Our reasoning is that unplanned parks formalize their mission statements once they already are active and therefore have clearer who are the stakeholders, what is the main purpose of the park, and what are its limitations. On the contrary, planned parks create their mission ex-ante, which makes it more difficult to define a mission statement that fits perfectly with future activities of the park.

\section{University Research Parks}

The growth in the number of university research parks has triggered an important debate on how these strategic enclaves of innovation and cutting-edge research stimulate growth and regional economic development. The origin of science parks can be found in the United States in 1950 aiming to create large industrial complexes of high-tech enterprises under the supervision of universities and the industry. The first example can be found in Silicon Valley. The initiative was led by Frederick Terman and William Shockley, professors from the University of Stanford 
who warned that a large area of the university was underexploited, becoming ideal for real estate development. They then started promoting a programme that encourages students to undertake research and doctoral theses with commercial applications, and provided them with venture capital. Up to date, approximately $60 \%$ of the revenues of companies from Silicon Valley come from firms created by students and teachers.

In 1951, the project of Silicon Valley was boosted thanks to the creation of the Stanford Industrial Park, a series of small industrial units that were made available for companies to be rented at low cost for the development of new technologies. Countries, regions, municipalities, universities and managers have tried to copy and replicate the singularities of Silicon Valley. The design and implementation of similar initiatives in different forms and processes have led to the creation of science parks all over the globe. Certainly, since the 90's science parks can be found almost everywhere and in a wide variety of environments and forms. Depending on the location and the scope we can distinguish among science parks, research parks, technology parks, business parks, technological districts/poles, and technopolis. Although differences exist, they are all popularly referred as "science parks". These are their common features:

(1) Interaction and association with an expert technological centre (usually a university);

(2) promote the creation and development of technology-based companies through incubation and spin-off processes;

(3) provide advanced support services to those institutions located inside;

(4) facilitate technology transfer processes among the different stakeholders, accelerating the commercialization of the results;

(5) are committed to the development of their regions by stimulating competition, quality and innovation amongst their associated institutions and businesses;

(6) require the management of spaces and resources by a specialized professional team.

In a university research park the university acquires a prominent role, acting as main driver for knowledge creation and knowledge transfer. For the purpose of this study we define a university research park as a "property-based venture which has existing or planned land and buildings designed primarily for private and public research and development facilities, high technology and science based companies, and support services". Its goal consists in "promoting research and development by the university in partnership with industry, assisting in the growth of new ventures, 
and promoting economic development" while "aiding the transfer of technology and business skills between the university and industry tenants".

When talking about the initial stages of university research parks two different strategies can be envisaged: In a planned-park, universities are provided with one or more buildings with the appropriate services in order to attract research groups and firms to locate inside and develop their activities there. The park itself is specifically created to generate a more dynamic and creative environment. However, there is no tangible evidence that this goal will be achieved and that the building and spaces that have been created will be used. Accordingly, one of the main difficulties behind this is the ability to attract a critical mass of scientific talent and knowledge-based companies. A well-developed marketing strategy is indeed needed to ensure the success of the park in the future.

Planned-parks are based on an internal design which has been drawn prior to starting with the activity. It is for that reason that unexpected obstacles may probably arise when implementing it. Moving from a paper-proposal to a 3D-reality is a very complex process that requires a powerful marketing strategy able to attract research groups, knowledge-based companies, venture capital companies and SMEs to move into the park. Successes and failures during the project may lead to modifications in the strategy, expansions and even changes in the relationships between the stakeholders.

Planned-parks are usually products of regional governmental initiatives in an agreement with a university. In order to convince companies to locate there, the initial stages are mainly concentrated in attracting renowned R\&D firms. Evidence suggests that better results are achieved if firms that are actually collaborating with the university are first invited to join the project. As any intended action on the territory, parks created following this strategy are powerful policy instruments that contribute to regional and economic development. By using housing as an urban proposal university research parks help creating a society of entrepreneurs and innovative corporations.

Contrary to the strategy of planned-parks, unplanned-parks require the existence of a critical research mass prior to the formalization of the park. This includes highly active research groups, incubator spaces to host spin-offs and advanced services for R\&D promotion and valorisation, among others. Parks are therefore created as a result of institutionalizing an endogenous dynamic environment, characterized by high quality services that boost research and technology transfer activities. Aiming at improving the externalities and the interrelations between the different stakeholders located in a same geographical 
enclave, parks are formalized and specific units are created, managing all the activities that emerged spontaneously.

Unplanned-parks are endogenous in their nature. Parks created following this strategy are the result of a previous deliberate strategy which takes advantage of the positive externalities arising from a geographical concentration, an agglomeration of knowledge and a resource sharing policy. The commercialization function is also essential in this strategy in order to attract new partners to locate in the park and thus, complete the clusterization puzzle. Perhaps the main challenge that planned-parks face has to do with the creation of the specific unit that will be in charge of managing the park. Because prior to the formalization of the park. The establishment of a new centralized unit might create some tensions that hamper the relationships between the stakeholders. In this respect, the development of a trustworthy relationship between these unit and the different stakeholders is of the main determinants of collaborative success.

\section{Data and method}

The Spanish public higher education system comprises 47 universities. Because information regarding the park's mission statements is not always publicly available on its web sites, we eliminated from the sample those university research parks from which we did not have data. Consequently, our final sample contained 24 university research parks which have an explicit mission statement. This sample includes universities located in 11 out of the 17 autonomous communities of Spain, which represents the $64 \%$ of the Spanish territory.

\section{Content analysis}

Content analysis has been used in prior studies as a qualitative research technique that allows the analysis of a written message. Following the study of Bartkus, Glassman, and McAfee (2006) we have used this technique to examine the presence of mission statements' stakeholders. When identifying and classifying the stakeholders, a keyword list was established. The terms are listed in Table 1. 
Table 1. Keywords to identify the different stakeholders

\begin{tabular}{|c|c|}
\hline Stakeholders & Keywords \\
\hline Customers & $\begin{array}{l}\text { consumers, customers, clients, local government, city council, } \\
\text { administration, nation, state, government, public administration, } \\
\text { council, companies, university, industry, university community, } \\
\text { technology centres, technology agents, entrepreneurs, } \\
\text { organizations, entities, R\&D units, business world, researchers, } \\
\text { business sector, professionals, and students }\end{array}$ \\
\hline Employees & employees, our people, work force, workers, and human capital \\
\hline Investors & $\begin{array}{l}\text { investors, university, nation, state, local government, city council, } \\
\text { government, public administration, administration, partners, } \\
\text { council, and promoters identified investors }\end{array}$ \\
\hline Suppliers & suppliers and partners \\
\hline Society & $\begin{array}{l}\text { national economies, environment, social goals, quality of life, } \\
\text { world, community, global, society, generate well-being, generate } \\
\text { employment, generate wealth, social needs and environment }\end{array}$ \\
\hline
\end{tabular}

As a second measure of the quality of the mission statement, we follow the approach used by Pearce and David (1987) who identify several components that could appear in a mission statement: target customers and markets, product and services, geographic domain, core technologies, commitment to survival, philosophy and values, and self-concept (see Table 2).

Table 2. Keywords to represent mission components

\begin{tabular}{|l|l|}
\hline Component & Keywords \\
\hline Target customers & $\begin{array}{l}\text { consumers, customers, clients, local government, city council, } \\
\text { administration, nation, state, government, public } \\
\text { administration, council, companies, university, industry, } \\
\text { university community, technology centres, technology agents, } \\
\text { entrepreneurs, organizations, entities, R\&D units, business } \\
\text { world, researchers, business sector, professionals, and } \\
\text { students }\end{array}$ \\
\hline
\end{tabular}




\begin{tabular}{|l|l|}
\hline $\begin{array}{l}\text { Product and } \\
\text { services }\end{array}$ & $\begin{array}{l}\text { business development, innovation, talent, knowledge and } \\
\text { technology transfer, technological development, technological } \\
\text { infrastructures, technology, space of excellence, knowledge, } \\
\text { value generation, knowledge management and value-added } \\
\text { services }\end{array}$ \\
\hline Geography & worldwide, geographic area, region, and country \\
\hline $\begin{array}{l}\text { commitment to } \\
\text { and profitability }\end{array}$ & $\begin{array}{l}\text { socio-economic development, benefits, productivity, growth, } \\
\text { efficiency, survival, profitability, values generation, } \\
\text { sustainability and success }\end{array}$ \\
\hline $\begin{array}{l}\text { Philosophy and } \\
\text { values }\end{array}$ & $\begin{array}{l}\text { honesty, harmony, well-being, integrity, fairness, responsibly, } \\
\text { social needs, generate well-being, generate employment, } \\
\text { cultural development and generate wealth }\end{array}$ \\
\hline Core technologies & - \\
\hline Self-concept & critical agent, important agent, key role \\
\hline Public image & be seen as, relevant \\
\hline
\end{tabular}

\section{Testing for differences between planned and unplanned parks}

The main purpose of this research is to explore potential differences in mission statement quality between the creation and the formulation strategy by comparing the stakeholders' groups and components mentioned in the mission statement. We expect that mission statements of parks that followed an entrepreneurial route (unplanned) will contain more stakeholders' groups and more components than planned parks.

Table 3 summarizes the number of stakeholders' groups and components depending on the creation strategy of the park. As shown, the number of stakeholder groups mentioned in the mission statement of planned parks tends to be lower. Out of the 16 parks that followed this creation strategy, nine refer to only one stakeholder. When analysing unplanned parks, the average number of stakeholders is above 3 . Table 3 also displays information regarding the number of components as defined by Pearce and David (1987). In this case, planned parks exhibit a higher number of components compared to unplanned parks. 
Table 3. Number of stakeholder groups/components from the mission statements reviewed.

\begin{tabular}{|l|l|l|l|l|l|l|l|l|l|}
\hline \multicolumn{7}{|l|}{ Number of stakeholder groups / components } \\
\hline & 1 & 2 & 3 & 4 & 5 & 6 & 7 & 8 \\
\hline Stakeholder groups & 0 & 3 & 4 & 1 & 0 & NA & NA & NA \\
\hline Unplanned & 9 & 5 & 1 & 1 & 0 & NA & NA & NA \\
\hline Planned & 9 & 1 & 2 & 1 & 2 & 2 & 0 & 0 \\
\hline Mission statement components & 0 & 1 & 3 & 2 & 6 & 2 & 3 & 0 & 0 \\
\hline Unplanned & 0 &
\end{tabular}

NA: Not applicable. We have defined only 5 types of stakeholder groups.

Aiming at testing for potential differences between mission statements from planned and unplanned parks, we conducted the Mann-Whitney U-test and t-test. Through the Mann-Whitney U-test method it is possible to test whether the observed differences between the number of components used in university research parks' mission statements (planned-parks and unplanned-parks) are significantly different. The analysis also considers a t-test of mean differences to further corroborate the findings obtained.

\section{Results and discussion}

Three main conclusions can be drawn from the analysis: (1) unplanned parks have a higher number stakeholders' groups (Bart, 1997) in their mission statements compared to planned parks, yet there is no statistically significance difference when comparing the number of components; (2) unplanned parks are more likely to mention the investors stakeholders ( $75 \%$ of the cases under analysis) within the mission statement formulation (in planned park stakeholders are rarely mentioned); (3) there is no relation between the number of Pearce and David's (1987) mission statements components and the strategy formulation of the mission statement. These results point in the direction that mission formulation strategy might lead to higher quality mission statement than the creation strategy, specifically in that the formulation strategy takes into consideration more stakeholders than the creation strategy. In the case of the university research parks mission statements that followed a formulation strategy do include investors among their stakeholders while university research parks which followed a creation strategy did not. 
We argue that the rationale behind these results lies in the creation strategy of the park. That is, when a university research park is formalized following the unplanned approach, the different stakeholders have already interacted between them; therefore, they are taken into account more easily when establishing and defining the mission of the park. These results are coherent with those reported by Bartkus, Glassman, and McAfee (2006). These authors suggest that including the most critical stakeholders in the mission statement may help executives focus their efforts on the core elements. In our case, this translates into saying that mentioning the investors in the mission statement of unplanned parks seems to advocate for a better alignment between the managers of the park and investors. Further studies should test whether including this stakeholder group in the mission statement has a tangible effect on the performance of the park.

Additional descriptives were calculated in order to shed new light on this non-effect between the creation strategy of the park and the components included in the mission statement. The analysis of the 24 mission statements collected reveals that the most common components are: target customers, products or services, and growth. That is, university research parks' mission statements tend to focus on customer requirements rather than on the image and philosophy of the park. We argue that these results might not be interpreted as a signal of poor quality, but as a sign of customer-orientation due to the entrepreneurial nature of parks.

Despite mission statements have a strong theoretical component our results indicate that, from a practitioner's point of view, they are also useful tools that help defining the goals and the strategic positioning of an organization (in this case, university research parks). Therefore, it is relevant to devote time and effort to have a sound statement, and particularly, one that is agreed upon the different stakeholders.

\section{Concluding remarks}

Although we believe that this study provides useful insights to the existing literature on mission statements, it is important to note that there are some limitations that constitute new research avenues for future studies. An important limitation refers to the access to mission statements and, as a consequence, of the sample size. It is also important to remark that this study refers to the specific analysis of Spanish URPs. New research efforts should be conducted in order to examine the patterns observed in other countries. In addition, future research might want to consider exploring the potential relationship between the financial performance of the park and the components included in the mission statement. 
According to Bart (1997) and Bartkus, Glassman, and McAfee (2006), including employees and society in the mission statement is related to superior financial performance. It would therefore be interesting to study whether a similar relationship is found between the investors' stakeholder group and the performance of the park depending on the creation strategy followed (planned vs. unplanned parks).

\section{References}

Alegre, I., Berbegal-Mirabent, J., Guerrero, A., \& Mas-Machuca, M. (2018). The real mission of the mission statement: A systematic review of the literature. Journal of Management \& Organization 24 (4): 456-473.

Bart, C. K. 1997. "Industrial firms and the power of mission." Industrial Marketing Management 26 (4): 371-383.

Bartkus, B. R., M. Glassman, and R. B. McAfee. 2000. "Mission Statements: Are they Smoke and Mirrors." Business Horizons 43 (6): 23-28.

Bartkus, B. R., M. Glassman, and R. B. McAfee. 2006. "Mission statement quality and financial performance." European Management Journal 24 (1): 86-94.

Berbegal-Mirabent, J., I. Alegre, and A. Guerrero. 2017. "University Research Parks and their impact on technology transfer activities." In Technological Innovation Networks: Collaboration and Partnership, Vol. 3, edited by B. Ran, 167-192. Charlotte, NC: Information Age Publishing.

David, F. R. 1989. "How companies define their mission." Long Range Planning 22 (1): 90-97.

Ireland, R. D., M.A. Hitt, and J. C. Williams. 1992. "Self-confidence and decisiveness: prerequisites for effective management in the 1990s." Business Horizons 35 (1): 36-43.

Leyden, D. P., A. N. Link, and D. S. Siegel. 2008. "A theoretical and empirical analysis of the decision to locate on a University Research Park." IEEE Transactions on Engineering Management 55 (1): 23-28.

Pearce, J. A., and F. David. 1987. "Corporate mission statements: The bottom line." Academy of Management Executive 1 (2): 109-116. 